\title{
Effective long-term temozolomide rechallenge in a macroprolactinoma
}

\author{
Benedetta Zampetti', Giorgia Simonetti², Roberto Attanasio ${ }^{3}$, Antonio Silvani² and \\ Renato Cozzi ${ }^{1}$
}

${ }^{1}$ Endocrinology Unit, Niguarda Hospital, Milan, Italy, 2Neurooncology Unit, Fondazione IRCCS Neurological Institute Carlo Besta, Milan, Italy, and ${ }^{3}$ Endocrinology Service, Galeazzi Institute IRCCS, Milan, Italy
Correspondence should be addressed

to B Zampetti

Email

benedettazampetti@yahoo.it

\section{Summary}

We describe the 20-year course of a 63-year-old male with a macroprolactinoma that acquired resistance to treatment and aggressive behavior after a 4-year successful treatment with cabergoline. He was submitted to multiple surgical resections by a skilled surgeon, fractionated radiotherapy and was eventually treated with temozolomide. After a first 6-month standard cycle, a relapse occurred and he was treated again successfully.

\section{Learning points:}

- Prolactinomas are the most frequent type of pituitary adenoma.

- They usually have a benign course.

- In most cases dopamine-agonist drugs, mainly cabergoline, are first-line (and usually only) treatment.

- Occasionally prolactinomas can have or acquire resistance to treatment and/or aggressive behavior.

- Temozolomide (TMZ), an oral alkylating drug, can be effective in such aggressive tumors.

- Multimodal treatment (surgery, radiation, cabergoline and TMZ) is warranted in aggressive pituitary tumors.

- We describe here successful rechallenge with TMZ after relapse occurring 18 months after a first TMZ cycle.

\section{Background}

Prolactinomas are the most common type of pituitary adenomas, accounting for about $40 \%$ of the total (1, 2). Endocrine symptoms are commonly related to hyperprolactinemia and hypogonadism. According to size, prolactinomas are classified as macro when the largest diameter is more than $10 \mathrm{~mm}$ at MRI. They are usually benign neoplasms but compression of adjacent anatomic structures may occur in large tumors, causing visual impairment and headache $(1,2)$.

First-line treatment is medication with dopamineagonist drugs, mainly cabergoline (Cab), capable of normalizing PRL levels and restore eugonadism in most cases, as well as to shrink tumor, thus relieving local compression $(1,2)$. Approximately $11 \%$ of prolactinomas are resistant to treatment with $\mathrm{Cab}$, despite maximal dose titration, and these tumors are typically treated with surgery (3). Radiotherapy is occasionally required.

In rare cases, prolactinomas may have or acquire an aggressive behavior, with uncontrolled tumor growth and PRL hypersecretion. These lesions can recur or reincrease despite multimodal therapy, including $\mathrm{Cab}$, multiple surgical resections and radiation $(1,2,3)$.

Here, we report the case of a man affected by macroprolactinoma that acquired an aggressive course after years on $\mathrm{Cab}$, requiring multiple cycles of chemotherapy with temozolomide (TMZ). 


\section{Case presentation}

In 1997, a 63-year-old male was referred to the Endocrine Unit for right hemianopia with visual acuity impairment and a huge invasive tumor with both infra- and suprasellar extension (maximum diameter $25 \mathrm{~mm}$ ). Hormonal evaluation showed pathologic hyperprolactinemia (PRL: $2300 \mu \mathrm{g} / \mathrm{L}$, normal range $(\mathrm{nr}): 4-15 \mu \mathrm{g} / \mathrm{L} ; 48760 \mathrm{mIU} / \mathrm{L}$, nr: $85-318 \mathrm{mIU} / \mathrm{L}$ ) and panhypopituitarism: morning cortisol $66 \mathrm{nM} / \mathrm{L}$ (nr: 165-607), free thyroxine: $86 \mathrm{pM} / \mathrm{L}$ (nr: 90-230), total testosterone: $2.1 \mathrm{nM} / \mathrm{L}$ (nr: 9.7-38), IGF-1: $4 \mathrm{nM} / \mathrm{L}$ (nr: 4-32).

Cab treatment $(2 \mathrm{mg} /$ week) was started, as well as replacement therapy with corticosteroids, thyroxine, and, later on, testosterone. PRL levels significantly decreased (to 618,81 and $34 \mu \mathrm{g} / \mathrm{L}-13$ 102, 1717, $721 \mathrm{mIU} / \mathrm{L}-$ after 1, 3 and 12 months, respectively). Visual acuity progressively improved up to normalization and MRI showed a significant progressive shrinkage, with the complete disappearance of the suprasellar portion of the tumor and the appearance of a partial empty sella. In the following 3 years, PRL remained stable and MRI showed no change.

After 4 years, while still on Cab $2 \mathrm{mg} /$ week, PRL increased up to $154 \mu \mathrm{g} / \mathrm{L} \quad(3265 \mathrm{mIU} / \mathrm{L})$ and MRI showed partial intrasellar regrowth of the adenoma. Notwithstanding Cab uptitration to $3.5 \mathrm{mg} /$ week, PRL gradually raised (up to $500 \mu \mathrm{g} / \mathrm{L}, 10600 \mathrm{mIU} / \mathrm{L}$ ) without further increase in tumor volume. Transsphenoidal surgery was performed in 2003. Histopathological examination showed pituitary adenoma with positive immunostaining for PRL and Ki67 2\%. After surgery, PRL was markedly lowered (to $33 \mu \mathrm{g} / \mathrm{L}, 700 \mathrm{mIU} / \mathrm{L}$ ), but MRI showed the persistence of an intrasellar tumor. Cab was administered again (maximum dosage: $3.5 \mathrm{mg} /$ week), but no change was observed in tumor volume. Two years after surgery, PRL was $200 \mu \mathrm{g} / \mathrm{L}(4240 \mathrm{mIU} / \mathrm{L})$ and the patient underwent a second transsphenoidal unsuccessful tumor resection. Histopathological examination was superimposable to the former; PRL values remained high $(310 \mu \mathrm{g} / \mathrm{L}, 6572 \mathrm{mIU} / \mathrm{L})$, without any change in tumor size. The patient underwent fractionated radiotherapy in 2006 (total dose: $39.6 \mathrm{~Gy}$ ).

After radiotherapy, PRL decreased $(87 \mu \mathrm{g} / \mathrm{L}$ and $57 \mu \mathrm{g} / \mathrm{L}$, - $1844 \mathrm{mIU} / \mathrm{L}$ and $1208 \mathrm{mIU} / \mathrm{L}$ - at 3 and 12 months, respectively) and a slight reduction of adenoma size was observed. In the next 4 years (on Cab $1.5 \mathrm{mg} /$ week), both PRL values and tumor size remained stable.

In 2011, 4 years after radiotherapy, PRL reincreased (to $773 \mu \mathrm{g} / \mathrm{L}, 16388 \mathrm{mIU} / \mathrm{L}$ ) as tumor size, and the patient underwent a third neurosurgery (immunohistochemistry was positive for PRL, no mitosis were shown, Ki67 was $2 \%$, MGMT evaluated by PCR was negative, i.e. the promoter was unmethylated). Neither PRL values were normalized $(350 \mu \mathrm{g} / \mathrm{L}-7420 \mathrm{mIU} / \mathrm{L}$ - immediately after surgery, and $564 \mu \mathrm{g} / \mathrm{L}-11957 \mathrm{mIU} / \mathrm{L}-1$ month later) nor MRI did show any change.

Six months later, PRL raised to $620 \mu \mathrm{g} / \mathrm{L}$ (13 $144 \mathrm{mIU} / \mathrm{L})$ but tumor volume remained stable without visual field alterations and clinical conditions of the patient remained excellent. Whole-body MRI did not show secondary lesions. Based on the worsening of disease in spite of three surgical resections by a skilled surgeon and one course of radiotherapy, chemotherapy with TMZ was added to the ongoing Cab treatment, using the schedule of $200 \mathrm{mg} / \mathrm{m}^{2}$ for 5 days every 28 days, up to six cycles. After the 3rd cycle, both PRL values $(256 \mu \mathrm{g} / \mathrm{L}, 5427 \mathrm{mIU} / \mathrm{L})$ and tumor size decreased. The treatment was well tolerated and safety parameters remained normal. After 1 year, 6 months after TMZ discontinuation, further tumor shrinkage was observed and PRL dropped to $76 \mu \mathrm{g} / \mathrm{L}(1611 \mathrm{mIU} / \mathrm{L})$.

PRL levels remained stable for 18 months following the end of TMZ, but eventually reincreased gradually up to $1219 \mu \mathrm{g} / \mathrm{L}(25843 \mathrm{mIU} / \mathrm{L})$, together with intrasellar increase of tumor size. A new TMZ course was started with the same schedule for 12 months. PRL values dropped again to $480 \mu \mathrm{g} / \mathrm{L}$ (10 176 mIU/L), $640 \mu \mathrm{g} / \mathrm{L}(13568 \mathrm{mIU} / \mathrm{L})$, $525 \mu \mathrm{g} / \mathrm{L}(11130 \mathrm{mIU} / \mathrm{L}), 500 \mu \mathrm{g} / \mathrm{L}(10600 \mathrm{mIU} / \mathrm{L}), 487 \mu \mathrm{g} / \mathrm{L}$ (10 $324 \mathrm{mIU} / \mathrm{L})$, and $553 \mu \mathrm{g} / \mathrm{L}(11723 \mathrm{mIU} / \mathrm{L})$ after 1, 2, 3, 4, 6 and 12 months from TMZ start, respectively, with a slight reduction of tumor size. No side effects developed. After the completion of the second TMZ cycle PRL levels were $525 \mu \mathrm{g} / \mathrm{L}(11130 \mathrm{mIU} / \mathrm{L}), 646 \mu \mathrm{g} / \mathrm{L}(13695 \mathrm{mIU} / \mathrm{L})$, $629 \mu \mathrm{g} / \mathrm{L}(13335 \mathrm{mIU} / \mathrm{L})$ and $1088 \mu \mathrm{g} / \mathrm{L}(36400 \mathrm{mIU} / \mathrm{L})$, at $6,9,12$ and 18 months, respectively. The patient is still in good clinical conditions and tumor size is not increased (Fig. 1).

\section{Discussion}

Our patient was affected by a macroprolactinoma that acquired resistance to treatment and an aggressive behavior after partially successful prolonged treatment with Cab (persistence of high PRL levels and tumor tissue). He required then multimodal treatment, with repeated surgery, and fractionated radiotherapy, and eventually chemotherapy with TMZ.

Pituitary adenomas are usually benign lesions, but mainly macroprolactinomas can occasionally acquire 


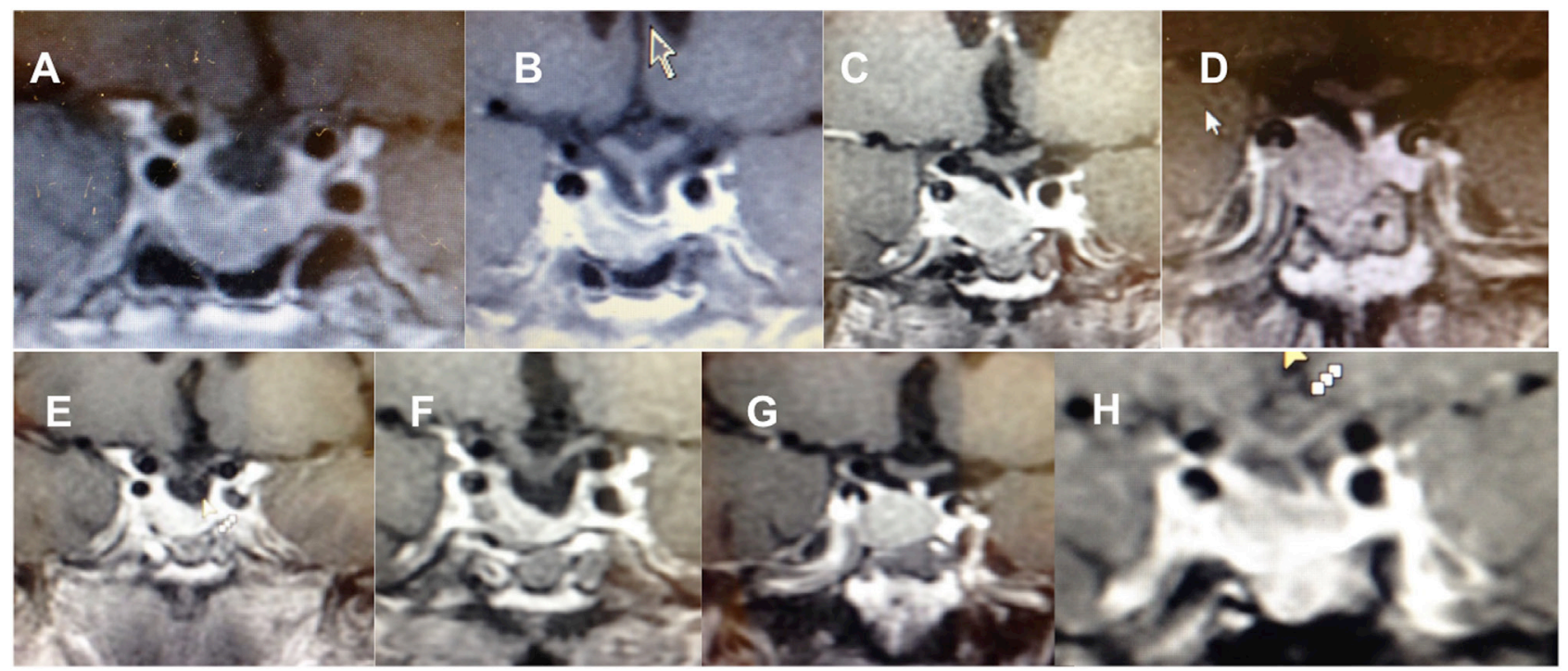

Figure 1

Serial images. (A) Before the first neurosurgery. (B) After the first neurosurgery. (C) After the third neurosurgery. (D) Four years after irradiation. (E) At 3 months during the first TMZ cycle. (F) At 6 months after the withdrawal of the first TMZ cycle. (G) At 18 months after the withdrawal of the first TMZ cycle. (H) At 6 months during the second TMZ cycle.

an aggressive behavior, thus representing a tremendous challenge for the endocrinologist. The European Society of Endocrinology (ESE) has just issued guidelines for the management of aggressive pituitary tumors and carcinomas (4). A prolactinoma is defined as resistant to treatment if PRL normalization and tumor shrinkage are not achieved in spite of appropriate dose titration $(1,2,3)$. A tumor is defined aggressive whenever it is radiologically invasive with unusually rapid growth rate or when clinically relevant tumor growth occurs despite optimal standard therapies (surgery, radiotherapy and conventional pharmacological treatments) (4). Only the presence of distant metastases defines pituitary carcinoma.

TMZ is a peroral alkylating drug that was approved initially for the treatment of glioblastoma, and eventually was demonstrated to be effective in aggressive pituitary tumors and carcinomas (5). An endogenous DNA repair protein, $\mathrm{O}(6)$-methylguanine methyltransferase (MGMT), can remove the methyl group and thereby potentially counteract the cytotoxic effect of TMZ.

A few cases of TMZ treatment in prolactinomas were described, most successful as this case. It was previously described that MGMT immunostaining in the tumor was predictive of treatment failure $(6,7)$. However, the multicentric French study showed that this was not the rule, and anyway it is worthwhile a three-cycle challenge to test individual TMZ sensitivity (8). Unfortunately, the determination of MGMT in our patient was not performed directly by immunohistochemistry but only indirectly by PCR evaluation of the methylation status of the promoter.

Almost all cases described in literature point to TMZ effectiveness in the treatment of resistant prolactinomas. A systematic review describing 23 aggressive prolactinomas and 19 PRL-secreting carcinomas showed TMZ efficacy in $75 \%$ as evaluated by PRL levels (8.3\% normalization and $8.3 \%$ progression) and in $76.5 \%$ as evaluated by tumor volume (1/34 complete response and 20.6\% progression) (9). These figures were superimposable to those reported by McCormack et al. (7). Even overall survival was improved by TMZ in a series of 43 patients (13 prolactinomas) (10).

TMZ is usually well tolerated (7). Whereas nausea and vomiting are generally well controlled with anti-emetics, bone marrow suppression prompted TMZ withdrawal in $11 \%$ of patients in the retrospective observational survey by ESE (7). The rechallenge with TMZ monotherapy was rarely reported in patients with disease recurrence after a first successful TMZ cycle, and it was unsuccessful in most cases (7). This case is thus an exception.

Many issues are still unresolved. Concerning molecular pattern, it is not yet established the role of MGMT, the strongest prognostic factor and powerful predictor of response to TMZ chemotherapy in patients with glioblastoma. It was described a strong association $(\mathrm{OR}=9.35 ; P=0.0030)$ between MGMT-negative staining 
and sensitivity to TMZ in 15 out of 20 prolactinomas (5). Whether additional molecular markers other than MGMT expression may predict treatment response is still unknown. However, both the drop of endocrine tumor marker (such as ACTH or PRL in hypersecreting tumors) and tumor volume at 3 months may prove useful tools for assessing the response to TMZ, limiting its use if not effective (5). Moreover, it should be investigated whether alternative regimens that increase the duration of exposure and the cumulative dose of TMZ, as employed for high-grade gliomas, might be more effective even for prolactinomas. Generally, only standard TMZ schedule $\left(150-200 \mathrm{mg} / \mathrm{m}^{2}\right.$ for 5 days every 28 days) has been investigated, but the 21-day continuous schedule at a lower daily dose $\left(85-125 \mathrm{mg} / \mathrm{m}^{2}\right)$ or a continuous metronomic schedule of $50 \mathrm{mg} / \mathrm{m}^{2} /$ day (11) might be tested to verify the potential effect on tumor as well as the best balance between efficacy and safety.

Also timing of chemotherapy should be clarified. To date, clinical guidelines by Endocrine Society (2), Pituitary Society (1) and ESE (4) recommend the use of TMZ only as a third line after standard medical treatment (with dopamine-agonist drugs) and neurosurgery/radiotherapy. In the light of more and more cases in the literature with a good response to TMZ, it will be important to consider TMZ as a second-line treatment, prior or together with RT in order to avoid neurotoxicities especially in young patients.

It is unclear whether and when TMZ can be safely discontinued after the achievement of tumor growth control. Likewise, it is uncertain the effect of stopping and restarting treatment, and it has not yet been explored the opportunity to prolong the treatment indefinitely in case of disease relapse after a first cycle of treatment.

Hence, it is necessary to standardize the use of TMZ, identifying specific molecular patterns that could predict clinical course and response to therapy. We still need to identify appropriately selected population where TMZ can be highly effective, in order to obtain individual tailoring of care. Large randomized controlled trials would be useful to evaluate the role of TMZ in patients affected by aggressive refractory pituitary adenomas, and the possible combination of TMZ with other cytotoxic drugs, but we are aware that it will be extremely difficult to collect such kind of data.

\section{Declaration of interest}

The authors declare that there is no conflict of interest that could be perceived as prejudicing the impartiality of the research reported.

\section{Funding}

This research did not receive any specific grant from any funding agency in the public, commercial or not-for-profit sector.

\section{Patient consent}

Written informed consent has been obtained from the patient for publication of the submitted article.

\section{Author contribution statement}

$B Z$ and R C were the endocrinologists involved in the care of the patient. $G$ $S$ and $A S$ were the neurooncologists responsible for $T M Z$ administration. $\mathrm{R}$ A wrote the paper.

\section{References}

1 Casanueva FF, Molitch ME, Schlechte JA, Abs R, Bonert V, Bronstein MD, Brue T, Cappabianca P, Colao A, Fahlbusch R, et al. Guidelines of the Pituitary Society for the diagnosis and management of prolactinomas. Clinical Endocrinology $2006 \mathbf{6 5}$ 265-273. (https://doi.org/10.1111/j.1365-2265.2006.02562.x)

2 Melmed S, Casanueva FF, Hoffman AR, Kleinberg DL, Montori VM, Schlechte JA, Wass JA \& Endocrine Society. Diagnosis and treatment of hyperprolactinemia: an Endocrine Society Clinical Practice Guideline. Journal of Clinical Endocrinology and Metabolism 201196 273-288. (https://doi.org/10.1210/jc.2010-1692)

3 Gillam MP, Molitch ME, Lombardi G \& Colao A. Advances in the treatment of prolactinomas. Endocrine Reviews 200627 485-534. (https://doi.org/10.1210/er.2005-9998)

4 Raverot G, Burman P, McCormack A, Heaney A, Petersenn S, Popovic V, Trouillas J, Dekkers OM \& European Society of Endocrinology. European Society of Endocrinology Clinical Practice Guidelines for the management of aggressive pituitary tumours and carcinomas. European Journal of Endocrinology 2018178 G1-G24. (https://doi.org/10.1530/EJE-17-0796)

5 Whitelaw BC, Dworakowska D, Thomas NW, Barazi S, Riordan-Eva P, King AP, Hampton T, Landau DB, Lipscomb D, Buchanan CR, et al. Temozolomide in the management of dopamine agonist-resistant prolactinomas. Clinical Endocrinology 201276 877-886. (https://doi org/10.1111/j.1365-2265.2012.04373.x)

6 Bush ZM, Longtine JA, Cunningham T, Schiff D, Jane JA Jr, Vance ML, Thorner MO, Laws ER Jr \& Lopes MB. Temozolomide treatment for aggressive pituitary tumors: correlation of clinical outcome with O-methylguanine methyltransferase (MGMT) promoter methylation and expression. Journal of Clinical Endocrinology and Metabolism 201095 E280-E290. (https://doi. org/10.1210/jc.2010-0441)

7 McCormack A, Dekkers OM, Petersenn S, Popovic V, Trouillas J, Raverot G, Burman P \& ESE Survey Collaborators. Treatment of aggressive pituitary tumours and carcinomas: results of a European Society of Endocrinology (ESE) survey 2016. European Journal of Endocrinology 2018178 265-276. (https://doi.org/10.1530/EJE-170933)

8 Raverot G, Sturm N, de Fraipont F, Muller M, Salenave S, Caron P, Chabre O, Chanson P, Cortet-Rudelli C, Assaker R, et al. Temozolomide treatment in aggressive pituitary tumors and pituitary carcinomas: a French multicenter experience. Journal of Clinical Endocrinology and Metabolism 201095 4592-4599. (https://doi. org/10.1210/jc.2010-0644)

9 Almalki MH, Aljoaib NN, Alotaibi MJ, Aldabas BS, Wahedi TS, Ahmad MH \& Alshahrani F. Temozolomide therapy for resistant 
Endocrinology,

Diabetes \& Metabolism

CASE REPORTS
B Zampetti and others

Temozolomide in a

macroprolactinoma
ID: 18-0092; October 2018

DOI: 10.1530/EDM-18-0092 prolactin-secreting pituitary adenomas and carcinomas: a systematic review. Hormones 201716 139-149. (https://doi.org/10.14310/ horm.2002.1729)

10 Lasolle H, Cortet C, Castinetti F, Cloix L, Caron P, Delemer B, Desailloud R, Jublanc C, Lebrun-Frenay C, Sadoul JL, et al.

Temozolomide treatment can improve overall survival in aggressive pituitary tumors and pituitary carcinomas. European Journal of Endocrinology 2017176 769-777. (https://doi.org/10.1530/EJE-160979)

11 Syro LV, Rotondo F, Ortiz L \& Kovacs K. Treatment of pituitary tumors with temozolomide: an update. Endocrine-Related Cancer 2018 25 T159-T169. (https://doi.org/10.1530/ERC-18-0015)

Received in final form 21 August 2018

Accepted 10 September 2018 